\title{
The Impact of Recent Queenloss and Colony Pheno- type on the Removal of Small Hive Beetle (Aethina tumida Murray) Eggs and Larvae by African Honeybee Colonies (Apis mellifera capensis Esch.)
}

\author{
Sebastian Spiewok ${ }^{1}$ and Peter Neumann ${ }^{2,3,4,5}$
}

revised July 4, 2006; accepted August 16, 2006

\begin{abstract}
The removal of small hive beetle $[=S H B]$ eggs and larvae was studied in queenright and recently queenless Cape honeybee, Apis mellifera capensis, colonies over a range of phenotypes. The overall removal efficiency was not influenced by phenotypes or queenstate, because all introduced eggs and larvae were removed within 24 hours. Queenless colonies removed them merely slower than queenright ones. The latter ones rejected up to 300 larvae within one hour. However, colonies undergoing preparation for absconding did not completely remove $S H B$ offspring, suggesting that removal efficiency was reduced. Since even small and recently queenless colonies effectively removed immature $S H B$, and no differences in the overall efficiency was found compared to A. m. scutellata we conclude that this defense behavior is well developed in African honeybees.
\end{abstract}

KEY WORDS: Aethina tumida; Apis mellifera; honeybee; parasite; small hive beetle; hygienic behavior.

\footnotetext{
${ }^{1}$ Institut für Zoologie, Martin-Luther-Universität Halle-Wittenberg, Hoher Weg 4, D-06099 Halle (Saale), Germany.

${ }^{2}$ Swiss Bee Research Centre, Agroscope Liebefeld-Posieux Swiss Federal Research Station ALP, Schwarzenburgstrasse 161, CH-3003 Bern, Switzerland.

${ }^{3}$ Department of Zoology and Entomology, Rhodes University, Grahamstown 6140, South Africa.

${ }^{4}$ Eastern Bee Research Institute of Yunnan Agricultural University, Kunming, Yunnan Province China.

${ }^{5}$ To whom correspondence should be addressed at; e-mail: peter.neumann@alp.admin.ch.
} 


\section{INTRODUCTION}

The small hive beetle, Aethina tumida Murray [= SHB], is a pest of honeybee, Apis mellifera, colonies native to sub-Saharan Africa (Lundie, 1940; Schmolke, 1974; Hepburn and Radloff, 1998; Neumann and Elzen, 2004). It became an invasive species and has been introduced into North America (1996), Egypt (2000), Australia (2002) and Europe (Neumann and Elzen, 2004; Ritter, 2004). In its native range, reproduction appears most successful in weak and stressed colonies or in recently abandoned honeybee nests (Lundie, 1940; Schmolke, 1974; Hepburn and Radloff, 1998; Neumann and Elzen, 2004). Thus, the role of colony strength and stress for the prevention of SHB reproduction seems to be important to understand the biology of $A$. tumida (Neumann and Elzen, 2004). Colony stress can arise from a variety of causes such as beekeeping manipulations, infestations with other parasites, lack of food stores or the loss of the queen. However, up to now no quantitative data on the role of colony stress for successful suppression of SHB reproduction inside honeybee nests is available.

The removal of SHB eggs and larvae is a resistance mechanism of honeybee colonies towards infestations. SHB lay their eggs directly on the combs, in cracks of the nests or even in sealed brood cells (Lundie, 1940; Ellis et al., 2003b). African honeybee workers remove SHB eggs (Swart et al., 2001; Neumann and Härtel, 2004) as well as bee brood infested by SHB (Ellis et al., 2003b, 2004), but are not able to remove all eggs laid in cracks (Neumann and Härtel, 2004). However, the larvae have to leave their protected sites after hatching and can then be removed by the workers (Lundie, 1940; Schmolke, 1974; Neumann and Härtel, 2004). The colonies in these previous studies were queenright and quite uniform in strength which may have masked the impact of colony stress and phenotypes. We expect relatively small and stressed colonies to be less efficient in removing SHB. Here, we investigate the impact of a wide range of colony phenotypes and recent queenloss on the removal of SHB eggs and larvae in colonies of the Cape honeybee, A. m. capensis.

\section{MATERIAL AND METHODS}

\section{Experimental Colonies}

Unrelated queenright colonies of $A$. $m$. capensis $(N=18)$ with different phenotypes were obtained from the endemic range of the Cape honeybee (Heidelberg, Western Cape, South Africa; Hepburn and Radloff, 1998). 
They were housed in 10-frame Langstroth hives with a brood box and a super in a research apiary in Grahamstown, Eastern Cape. While the supers were empty, the brood boxes contained honey, pollen and brood frames. Prior to the experiments, the colonies were given four days to settle down to limit disturbance-induced absconding (Spiewok et al., 2006). To induce colony "stress", the queens were removed from six small colonies one day prior to the experiments. Small colonies were dequeened in order to amplify the potential combined effects of stress and small size on the removal of SHB offspring. The natural infestation level of all colonies with SHB adults was very low $(<5$ each $)$.

\section{Egg Removal}

SHB were reared in the laboratory following routine protocols (Mürrle and Neumann, 2004). For $12 \mathrm{~h}$, adult SHB were allowed to oviposit in small gaps between two microscope slides (method developed by JS Pettis; cited in Somerville, 2003). Then, eggs were transferred with a paint brush on new slides and one pair of slides was placed on top of the frames of each colony $(N=120$ eggs in total). After one, two, three, five, eight, ten and $24 \mathrm{~h}$, the lids were briefly removed and the remaining eggs were counted using magnifying glasses $[10 \times]$ and then reintroduced at the same within-hive location.

\section{Larva Removal}

On three sequential days, dry SHB larvae were obtained from the laboratory rearing (see Neumann and Härtel, 2004) and introduced into 16 Petri dishes $(N=100$ each). The dishes were introduced into each test colony on top of the frames following the protocol of Neumann and Härtel (2004). After one, two, three, five, eight, ten and $24 \mathrm{~h}$, the dishes were briefly removed to count the number of remaining larvae. Then the dishes were reintroduced at the same within-hive location. Five days later, the experiment was repeated with a total of 300 SHB larvae in three dishes per queenright $(N=9)$ and queenless colony $(N=6)$. To control for the escape rate of larvae from the Petri dishes, seven dishes with 100 larvae each were introduced into Apide ${ }^{\odot}$-mating boxes and the number of remaining larvae in the open dishes was counted after $24 \mathrm{~h}$.

\section{Colony Phenotype Data}

One day after the removal experiments with eggs and 100 SHB larvae, the colony phenotypes (size, area of open and sealed brood, pollen and 
honey) were evaluated for all test colonies using the standard Liebefelder method of colony estimation (Gerig, 1983; Imdorf et al., 1987).

\section{Data Analysis}

Proportions $p$ of remaining eggs and larvae were $\operatorname{arcsine} \sqrt{ } p$ transformed for analyses. Friedman ANOVAs were performed to test for differences in the proportions of remaining larvae between the three sequential days (see above). The proportions of remaining eggs and larvae were analyzed for differences between queenless and queenright colonies using Mann-Whitney $U$-tests. A Kruskal-Wallis ANOVA and Mann-Whitney $U$-tests were performed to compare the proportions of remaining larvae in the controls with those in the queenless and queenright colonies after $24 \mathrm{~h}$. To test for differences in the proportions of remaining larvae between the treatments with 100 and 300 larvae, the data were subjected to paired $t$-tests. Furthermore, analyses of regression were performed between the colony phenotype data and the proportions of remaining eggs and larvae. For these regressions, the amount of open and capped brood was combined. The phenotype data of queenless and queenright colonies were compared using Mann-Whitney $U$-tests and the variance of the colony sizes was compared to the study of Neumann and Härtel (2004) using a F-test. Finally, the proportions of remaining SHB larvae in the queenright colonies were compared with the data for $A$. m. scutellata (Neumann and Härtel, 2004) using $t$-tests. Data given in the text are medians with 1. quartile and 3. quartile. Experimental colonies absconding within one week after the respective experiment were not included into the statistical analyses. Bonferroni adjustments to the levels of significance were included. All tests were performed using Statistica. ${ }^{\odot}$

\section{RESULTS}

\section{Absconding}

Two queenright colonies absconded between the removal experiments with 100 and 300 larvae and three queenless ones within one week after the experiment with 300 larvae. The two absconding queenright colonies were not included in the statistical analyses for the experiments with eggs and 100 larvae, because in contrast to the non-absconding colonies $78 \%-92 \%$ of the eggs and $8 \%-62 \%$ of the larvae remained after $24 \mathrm{~h}$. Similarly, the three absconding queenless colonies were not taken into account for the last removal experiment with 300 larvae. 


\section{Egg Removal}

All non-absconding colonies removed the SHB eggs within three hours. No eggs remained in the queenright colonies $(N=10)$ already after one hour, while $18 \%[0 ; 48]$ of the eggs remained in the queenless ones. Casual observations showed that the workers ate the eggs. Three of the six queenless colonies removed all eggs within one hour, the other ones within the following two hours. Therefore, queenright colonies rejected significantly more eggs than the queenless ones only within the first hour $(Z=-2.27, p=0.023)$.

\section{Larva Removal}

\section{Removal of 100 SHB Larvae}

At the colony entrances, workers were observed carrying the SHB larvae between their mandibles out of the colonies. There were no significant differences in the proportions of remaining larvae between the three sequential days (queenless colonies: $1 \mathrm{~h}: \chi^{2}=3.33, d f=2, p=0.189$; $2 \mathrm{~h}: \chi^{2}=1.73, p=0.420$; queenright colonies: $1 \mathrm{~h}: \chi^{2}=4.00, p=0.135 ; 2 \mathrm{~h}$ : $\chi^{2}=2.00, p=0.368$ ). Thus, the data of the three days were pooled for every colony and mean values were used for further analyses. After $24 \mathrm{~h}$, the larvae were entirely removed from all non-absconding colonies (Fig. 1). Seven queenright colonies removed all larvae within one hour. The proportions of remaining larvae were significantly lower in queenright colonies than in queenless ones during the first eight hours $(1 \mathrm{~h}: Z=1.99, p=0.046 ; 2 \mathrm{~h}$ : $Z=2.51, p=0.012 ; 3 \mathrm{~h}: Z=2.51, p=0.012 ; 5 \mathrm{~h}: Z=2.85, p<0.005 ; 8 \mathrm{~h}:$ $Z=2.39, p=0.020 ; N=16)$ but not anymore after ten hours $(10 \mathrm{~h}: Z=1.89$, $p=0.059)$. Since hardly any larvae $(2[0 ; 6]$ escaping larvae) left the control dishes, significant higher proportions of larvae remained in the controls than in the colonies after $24 \mathrm{~h}(H=21.16, p<0.001$; queenright colonies vs. controls: $Z=-3.84, p<0.001$; queenless colonies vs. controls: $Z=3.18$, $p<0.002)$.

\section{Removal of 300 SHB Larvae}

The non-absconding queenright $(N=9)$ and queenless colonies $(N=3)$ removed all larvae within 24 h (Fig. 2); two queenright ones rejected them even within one hour. No significant differences were found in the proportions of remaining larvae between the treatment with 100 and 
Remaining larvae [\%]

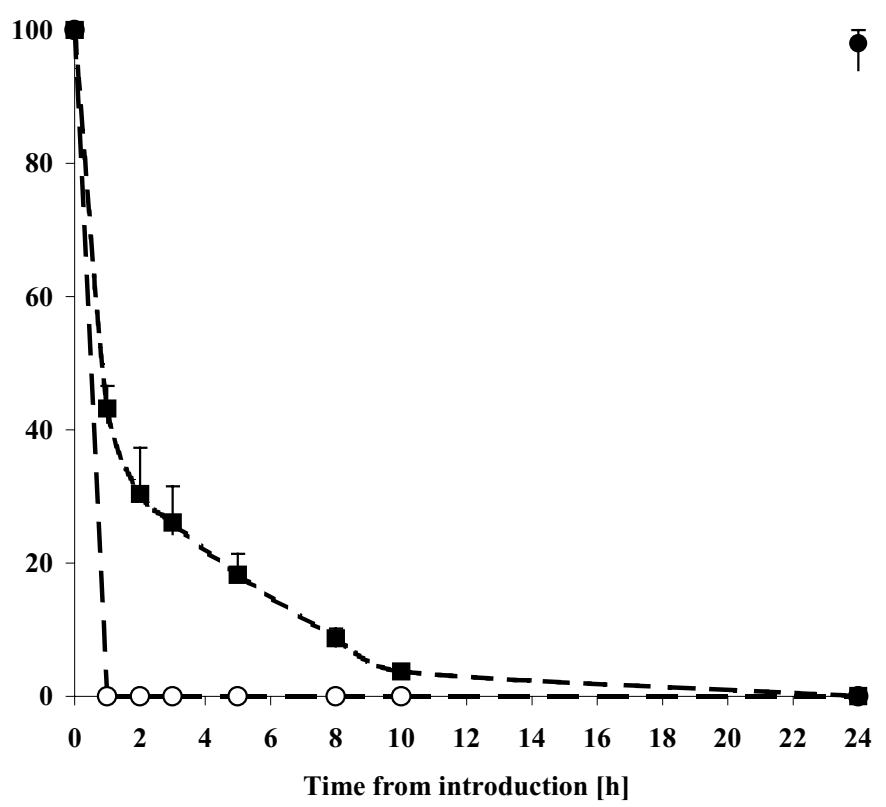

Fig. 1. Proportions of remaining larvae (100 larvae per colony) in nonabsconding queenless (squares) and queenright (open circles) A. m. capensis colonies and in the controls (filled circles). Medians and 1st and 3rd quartiles are shown.

300 larvae in the queenright colonies ( $1 \mathrm{~h}: t=2.22, d f=8, p=0.057)$. Since only three non-absconding queenless colonies remained in this experiment, no statistical analyses were performed with this group.

\section{Colony Phenotype Data}

The phenotypes are shown in Table I. The colonies showed a broad range of sizes from 2066 up to 16666 workers (mean $=9198 \pm 4656$ workers). Queenless colonies had significantly less pollen $(Z=2.48, p=0.013)$, honey $(Z=2.00, p=0.045)$, open brood $(Z=2.60, p=0.009)$, capped brood $(Z=2.00, p=0.045)$ and bees $(Z=2.65, p=0.008)$ compared to the queenright ones. No significant regressions were found between the colony phenotypes and the proportions of remaining eggs and larvae (Table II). The variance of the investigated range of colony sizes is significantly larger than 


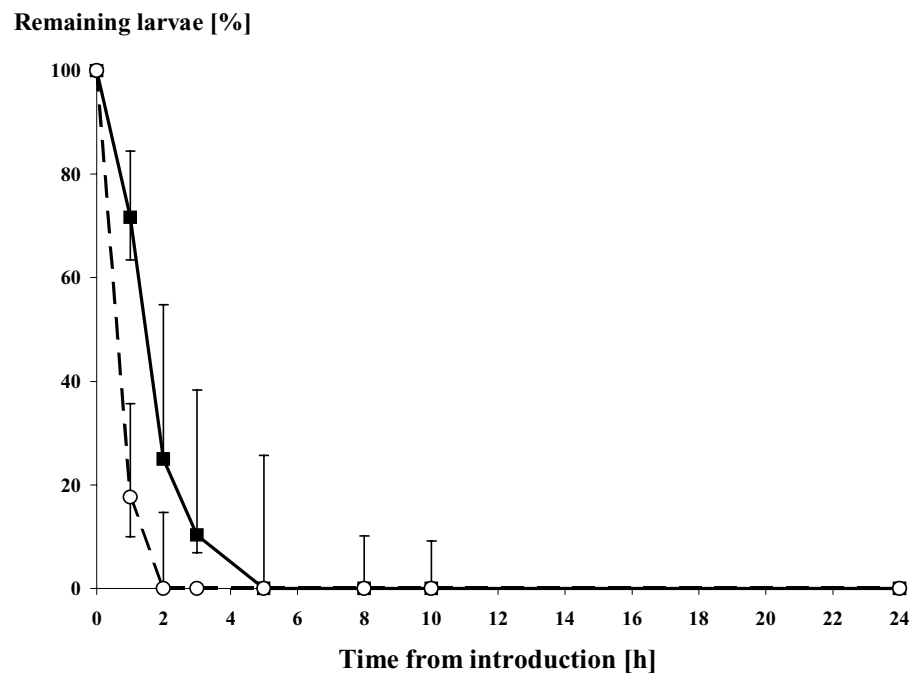

Fig. 2. Proportions of remaining larvae (300 larvae per colony) in nonabsconding queenless (squares) and queenright (open circles) A. m. capensis colonies. Medians are shown as well as 1st and 3rd quartiles for queenright colonies.

in a previous study on $A$. $m$. scutellata $(F=7.35, p<0.05$; Neumann and Härtel, 2004: $7387 \pm 1765$ workers, range: 4290 to 9035$)$.

\section{Comparisons with A. m. scutellata}

Cape honeybee colonies rejected a significantly higher proportion of larvae than $A$. m. scutellata ones only during the first two hours $(1 \mathrm{~h}: t=3.45$, $d f=15, p=0.004 ; 2 \mathrm{~h}: t=2.60, p=0.020)$. Otherwise, no significant differences were found ( $3 \mathrm{~h}: t=1.08, p=0.299$, data for $A$. $m$. scutellata pooled for the 2 nd and 4 th hour). Both subspecies completely removed all larvae within $24 \mathrm{~h}$.

\section{DISCUSSION}

Our results show that neither recent queenloss nor the tested range of colony phenotypes significantly influence the overall efficiency of the removal of SHB eggs and larvae by Cape honeybee colonies. On the one hand, colonies which recently lost their queens removed the beetle 
Table I. Colony Phenotypes of the Non-absconding Queenright and Queenless A. m. capensis Colonies

\begin{tabular}{cccccc}
\hline & \multirow{2}{*}{$\begin{array}{c}\text { Colony size } \\
\text { Colonies }\end{array}$} & \multicolumn{2}{c}{ Brood $\left(\mathrm{dm}^{2}\right)$} & & \\
\cline { 3 - 4 } & (bees & Open & Capped & Pollen $\left(\mathrm{dm}^{2}\right)$ & Honey $\left(\mathrm{dm}^{2}\right)$ \\
\hline Queenright & & & & & \\
1 & 15564 & 41.32 & 48.48 & 8.26 & 31.40 \\
2 & 16666 & 28.10 & 44.63 & 17.63 & 47.38 \\
3 & 15289 & 34.71 & 58.95 & 13.77 & 70.52 \\
4 & 15426 & 21.49 & 31.95 & 12.12 & 72.17 \\
5 & 9641 & 35.26 & 43.52 & 11.02 & 78.78 \\
6 & 7162 & 11.02 & 33.06 & 1.10 & 22.04 \\
7 & 6198 & 15.43 & 2.20 & 0.00 & 30.85 \\
8 & 11983 & 0.00 & 0.55 & 7.71 & 19.83 \\
9 & 10261 & 24.79 & 14.32 & 9.92 & 52.89 \\
10 & 7024 & 15.98 & 11.57 & 3.86 & 15.98 \\
Mean \pm SD & $11521 \pm 4016$ & $22.81 \pm 12.62$ & $28.92 \pm 20.56$ & $8.54 \pm 5.60$ & $44.19 \pm 23.52$ \\
\hline Queenless & & & & & \\
11 & 6198 & 0.00 & 1.10 & 0.00 & 15.43 \\
12 & 3581 & 6.06 & 7.16 & 1.10 & 29.75 \\
13 & 3443 & 3.86 & 5.51 & 1.10 & 0.55 \\
14 & 8126 & 4.41 & 0.00 & 6.61 & 27.55 \\
15 & 2066 & 0.00 & 2.75 & 0.00 & 17.08 \\
16 & 8540 & 1.10 & 13.22 & 1.65 & 51.24 \\
Mean \pm SD & $5326 \pm 2689$ & $2.57 \pm 2.55$ & $4.96 \pm 4.85$ & $1.74 \pm 2.47$ & $23.60 \pm 17.08$ \\
\hline Total & & & & & \\
Mean \pm SD & $9198 \pm 4656$ & $15.22 \pm 14.15$ & $19.94 \pm 20.12$ & $5.99 \pm 5.69$ & $36.47 \pm 23.13$
\end{tabular}

offspring slower than the queenright ones, indicating that such colony stress has a negative impact. On the other hand, no eggs or larvae remained even in any of these small and stressed colonies. However, both eggs and larvae remained in colonies which absconded within one week after the experiments, suggesting that the preparation for disturbance-induced absconding (Spiewok et al., 2006) reduces colony efficiency with respect to the removal of SHB offspring.

Table II. Analyses of Regression Between Colony Phenotypes and the Proportions of Remaining SHB Eggs and Larvae after $1 \mathrm{~h}$

\begin{tabular}{llccc}
\hline Experiment & Queenstate & $r^{2}$ & $F$ & $p$ \\
\hline 120 eggs & Queenless & 0.66 & 0.48 & 0.777 \\
100 larvae & Queenless & 0.54 & 2.46 & 0.442 \\
100 larvae & Queenright & 0.36 & 2.13 & 0.241 \\
300 larvae & Queenright & 0.78 & 8.13 & 0.033 \\
\hline
\end{tabular}

Notes. No significant regressions were found at the Bonferroni adjusted level of significance $\alpha=0.025$. 
The high efficiency of non-absconding colonies is illustrated by the removal of even 300 larvae within one hour from two queenright colonies. This quick colony response is in line with previous studies on African honeybees (Lundie, 1952; Schmolke, 1974; Neumann and Härtel, 2004) and suggests that recruitment of workers might be involved. However, the size of the colony does not influence the removal performance, as no correlations were detected between colony phenotypes and the proportions of remaining SHB offspring. Similarly, correlations were not found between honeybee colony size and defense against the greater wax moth, Galleria mellonella, probably because in smaller colonies a higher proportion of workers participates in nest defense (Eischen et al., 1986). Likewise, recent queenloss, which we used to induce colony stress, did not negatively influence the overall colony efficiency, although these colonies were also smaller and had fewer stores than the queenright ones. This suggests that colony phenotypes and recent queenloss alone are less likely to explain successful reproduction of SHB in Cape honeybee colonies.

SHB can oviposit inside capped brood cells (Ellis et al., 2003b) but such infested brood is also rejected (Ellis et al., 2004). Small colonies may have problems to remove the less easily accessible SHB offspring, but strong African colonies reject adult SHB from the combs and thereby prevent oviposition on the combs (Schmolke, 1974). Furthermore, SHB also oviposit in cracks (Lundie, 1940) and workers are not able to remove completely these eggs (Neumann and Härtel, 2004). Thus, larvae are likely to hatch in infested colonies. However, when they leave the cracks for feeding, even a high number of larvae is likely to be removed as shown in this study. As a consequence, a successful reproduction of SHB in honeybee colonies might be facilitated by a decrease in removal efficiency of the bees. This could be the case when the workers have to cope simultaneously with SHB offspring and a high number of adult SHB, e.g. by patrolling (Swart et al., 2001) and prison guarding (Neumann et al., 2001; Ellis et al., 2003a) and/or additional diseases or parasites (e.g. Galleria mellonella, Varroa destructor, etc.). Another possibility of low efficiency is likely to be the period of preparation prior to disturbance-induced absconding (Spiewok et al., 2006). In contrast to the remaining colonies, the absconding ones did not completely remove the SHB eggs and larvae. During absconding, which is common in African honeybee subspecies, the whole colony leaves the nest and settles down at a new site (Hepburn and Radloff, 1998). Workers of colonies undergoing preparation for absconding are urged to increase their energy intake by consuming most if not all of their stores and cannibalizing brood (Spiewok et al., 2006). Since the nest will be abandoned soon anyway, the threshold of workers to remove SHB eggs and larvae is probably increased. Similarly, colonies of the Asian honeybee A. cerana preparing for 
migration do not defend their nests anymore against intruders such as ants or wax moths (Punchihewa et al., 1990).

Queenright Cape honeybee colonies removed SHB larvae even quicker than those of $A$. m. scutellata (Neumann and Härtel, 2004), but both subspecies removed all larvae within 24 hours. Since $A$. $m$. scutellata colonies and even fairly small and recent queenless $A$. $m$. capensis ones show a highly efficient removal behavior, this trait seems to be well expressed in African honeybee subspecies even under unfavorable conditions. This is probably one reason for the apparent resistance of African honeybees towards SHB infestations. However, as slight differences between African subspecies are detectable, these may also exist between African and European subspecies, resulting in the higher susceptibility of the latter. Ellis et al. (2004) found no differences in the removal performance of SHB infested bee brood between queenright, uniform Cape honeybee and European colonies, but it remained unclear, if the bees detected the SHB offspring or the damaged brood, on which the possibly hatched larvae were feeding. Moreover, effects of colony phenotypes and stress on the resistance of colonies to SHB infestations may be different in European subspecies. Hitherto, data on the removal of SHB eggs and larvae by European honeybee colonies comparable to this study are not available. Therefore, we suggest to conduct a similar study with colonies of European origin to shed further light on the role of behavior for the resistance of honeybees to infestations with SHB.

\section{ACKNOWLEDGMENTS}

We are grateful to U Epperlein for technical assistance and M Kramer (USDA Beltsville) for statistical advice. Financial support was granted by a Visiting Professorship at Rhodes University and an Emmy Noether fellowship of the DFG [PN].

\section{REFERENCES}

Eischen, F. A., Rinderer, T. E., and Dietz, A. (1986). Nocturnal defensive responses of Africanized and European honey bees to the greater wax moth (Galleria mellonella L.). Anim. Behav. 34: 1070-1077.

Ellis, J. D., Holland, A. J., Hepburn, H. R., Neumann, P., and Elzen, P. J. (2003a). Cape (Apis mellifera capensis) and European (Apis mellifera) honey bee guard age and duration of guarding small hive beetles (Aethina tumida). J. Apic. Res. 42: 32-34.

Ellis, J. D., Richards, C. S., Hepburn, H. R., and Elzen, P. J. (2003b). Oviposition by small hive beetles elicits hygienic responses from Cape honeybees. Naturwissenschaften 90: 532-535. 
Ellis, J. D., Delaplane, K. S., Richards, C. S., Hepburn, R., Berry, J. A., and Elzen, P. J. (2004). Hygienic behaviour of Cape and European Apis mellifera (Hymenoptera: Apidae) toward Aethina tumida (Coleoptera: Nitidulidae) eggs oviposited in sealed brood cells. Ann. Entomol. Soc. Am. 97: 860-864.

Gerig, L. (1983). Lehrgang zur Erfassung der Volksstärke. Schweiz. Bienen-Zeitung 106: 199_ 204.

Hepburn, H. R., and Radloff, S. E. (1998). Honeybees of Africa. Springer Verlag, Berlin, Heidelberg, New York.

Imdorf, A., Bühlmann, G., Gerig, L., Kilchenmann, V. and Wille, H. (1987). Überprüfung der Schätzmethode zur Ermittlung der Brutfläche und Anzahl Arbeiterinnen in freifliegenden Bienenvölkern. Apidologie 18: 137-146.

Lundie, A. E. (1940). The small hive beetle Aethina tumida. Science Bulletin 220, Dep. Agr. Forestry, Government Printer, Pretoria, South Africa.

Lundie, A. E. (1952). The principal diseases and enemies of honey bees. S. Afr. Bee J. 27: 13-15.

Mürrle, T., and Neumann, P. (2004). Mass production of small hive beetles (Aethina tumida Murray, Coleoptera: Nitidulidae). J. Apic. Res. 43: 144-145.

Neumann, P., and Elzen, P. J. (2004). The biology of the small hive beetle (Aethina tumida Murray, Coleoptera: Nitidulidae): Gaps in our knowledge of an invasive species. Apidologie 35: 229-247.

Neumann, P., and Härtel, S. (2004). Removal of small hive beetle (Aethina tumida) eggs and larvae by African honeybee colonies (Apis mellifera scutellata). Apidologie 35: 31-36.

Neumann, P., Pirk, C. W. W., Hepburn, H. R., Solbrig, A. J., Ratnieks, F. L. W., Elzen, P. J., and Baxter, J. R. (2001) Social encapsulation of beetle parasites by Cape honeybee colonies (Apis mellifera capensis Esch.). Naturwissenschaften 88: 214-216.

Punchihewa, R. W. K., Koeniger, N., and Howpage, D. (1990) Absconding behaviour of Apis cerana in Sri Lanka. In Proceedings of the 11th International Congress of IUSSI, India, pp. $106-107$.

Ritter, W. (2004). Beutenkäfer in Portugal. Deutsches Bienen J. 12(12): 14.

Schmolke, M. D. (1974). A study of Aethina tumida: the small hive beetle. Project Report, University of Rhodesia.

Somerville, D. (2003). Study of the small hive beetle in the USA. Report for the Rural Industries Research and Development Corporation, NSW Agriculture, RIRDC Publication No $03 / 050$.

Spiewok, S., Neumann, P., and Hepburn, H. R. (2006). Preparation for disturbance-induced absconding of Cape honeybee colonies (Apis mellifera capensis Esch.). Ins. Soc. 53: 27 31.

Swart, J. D., Johannsmeier, M. F., Tribe, G. D., and Kryger, P. (2001). Diseases and pests of honeybees. In: Johannsmeier, M. F. (ed.) Beekeeping in South Africa, 3rd edition, revised, Plant Protection Research Institute Handbook No. 14, Agricultural Research Council of South Africa, Pretoria, South Africa, pp. 198-222. 